\title{
Influência do Processamento da Ração no Desempenho e Sobrevivência da Tilápia do Nilo Durante a Reversão Sexual
}

\author{
Fábio Meurer ${ }^{1}$, Carmino Hayashi ${ }^{2}$, Wilson Rogério Boscolo ${ }^{3}$
}

\begin{abstract}
RESUMO - Este experimento foi realizado no Laboratório de Aquicultura da Universidade Estadual de Maringá, objetivando avaliar rações com diferentes formas de processamento sobre o desempenho e sobrevivência de larvas de tilápia do Nilo durante a fase de reversão sexual. Foram utilizados 540 larvas distribuídos em 18 aquários de $54 \mathrm{~L}$ em um delineamento completamente casualizado, com três tratamentos e seis repetições. O período experimental foi de 28 dias a uma temperatura média de $21,9 \pm 0,1^{0} \mathrm{C}$ de manhã e $22,7 \pm 0,3^{0} \mathrm{C}$ à tarde. Foi formulada uma ração $(38,6 \%$ de proteína digestível e $3800 \mathrm{kcal} / \mathrm{kg}$ de energia digestível) diferindo quanto à forma de processamento (farelada (RF), pastosa (RP) e micropeletizada (RM)). Não foram observadas diferenças $(\mathrm{P}>0,05)$ quanto ao peso final e a condição corporal, entretanto a biomassa final das larvas alimentadas com RF foi superior, em relação aos que receberam RP e RM. A sobrevivência das larvas que receberam RP e RF respectivamente, foram semelhantes e superiores àquelas alimentadas com RM. Portanto, conclui-se que utilizando-se a moagem dos ingredientes da ração em peneira de 0,5 mm, para larvas de tilápia do Nilo durante a reversão sexual, a forma farelada de ração é a mais adequada.
\end{abstract}

Palavras-chave: larvicultura, processamento, ração farelada, ração micropeletizada, ração pastosa, tilápia do Nilo

\section{Influence of Diet Processing Form on Performance and Survival of Nile Tilapia During Sex Revert Phase}

\begin{abstract}
This work was carried out at Aquicultura Laboratory of Maringá State University, to evaluate the different processing form of diets on Nile tilapia fry performance and survive, during sexual revert phase. Was utilized 540 fry distributed, on completely randomized design with three treatments and six replications, in eighteen $54 \mathrm{~L}$ aquarium and one aquarium with $30 \mathrm{Nile}$ tilapia fry was considered an experimental unit. The experimental period was 28 days with average temperatures of $21.9 \pm 0.1^{\circ} \mathrm{C}$ in the morning and $22.7 \pm 0.3^{0} \mathrm{C}$ in the afternoon. The diet was formulated $(38.6 \%$ of digestible protein and $3800 \mathrm{kcal} / \mathrm{kg}$ digestible energy) differing only about processing form (crumble [MD], meal [ND] and pasty [PD]). No difference was observe to final weight and body condition, but to biomass production, the fry submitted of ND treatment was higher than MD and PD treatments, that were equal. To survive ND and PD were equal and higher than MD treatment. It was concluded that, with $0.5 \mathrm{~mm}$ of mealling degree, the meal diets was most adequate to Nile tilapia fry, during sex revert phase.
\end{abstract}

Key Words: diet processing, fry, Nile tilapia, meal ration, crumble ration, pasty ration

\section{Introdução}

A tilapicultura vem se mostrando uma ótima alternativa para a piscicultura de água doce e estuarina. A expansão do cultivo da tilápia do Nilo (Oreochromis niloticus), deve-se ao ótimo desempenho, alta rusticidade, facilidade de obtenção de alevinos, adaptabilidade aos mais diversos sistemas de criação, grande aceitação no mercado de lazer (pesque-pague) e alimentício (frigoríficos), pelas qualidades nutritivas e organolépticas do seu filé.

A etapa de larvicultura é de fundamental importância para a obtenção de animais em quantidade e de qualidade, para as fases posteriores de criação, sendo que a nutrição adequada exerce grande influência e é pré-requisito básico para o sucesso da criação (Hayashi et al., 2001). Um dos principais entraves da atividade é justamente a alimentação nesta fase, pois para a maioria das espécies está relacionada ao fornecimento de organismos planctônicos (Cestarolli et al., 1997; Galvão et al., 1997; Soares et al., 1997; Radünz-Neto, 1999; Soares et al., 2000).

A utilização de dietas artificiais como única fonte de alimento não tem resultado em sucesso para a maioria das espécies, porém o seu consórcio com o alimento vivo tem sido mais eficiente (Fermin \&

1 Zootecnista, M.S., Professor Assistente do curso de Medicina Veterinária da Pontifícia Universidade Católica do Paraná (PUCPR), Campus de Toledo, Av. da União, 500, Jardim Coopagro, CEP: 85902-532, Toledo-PR. E.mail: fabiomeurer@pop.com.br; fmeurer@rla01.pucpr.br

2 Prof. Titular do Depto de Biologia - UEM. E.mail: chayashi@uem.br

3 Zootecnista, Msc., Prof. de Eng. de Pesca/UNIOESTE, doutorando/PPZ/UEM. E.mail: wrboscolo@bol.com.br

* Parte da dissertação de mestrado do primeiro autor. 
Recomenta, 1988; Ajah, 1997; Quin et al; 1997; Di Lauro \& Krise, 1998; Hayashi et al., 2001). Entretanto, a tilápia do Nilo, não depende deste consórcio, pois aceitam e desenvolvem-se bem no período larval alimentando-se de ração (Santiago et al., 1987; Meurer et al., 2002). De acordo com Souza et al. (2000) podem ser utilizados os farelos de soja, girassol e canola como fonte de $50 \%$ da proteína da dieta, fatores estes que contribuem para o baixo custo na produção de seus alevinos (Lahav \& Ra'nam, 1997).

De acordo com Kubitza (1997), a vantagem das larvas da tilápia do Nilo é que estas possuem o trato digestivo completo, com capacidade de digestão enzimática, portanto com potencial para a utilização de rações artificiais. Ao contrário de espécies como pacu (Piaractus mesopotamicus) e tambaqui (Colossoma macropomum), entre outros, as quais necessitam de alimentos vivos, pois nesta fase possuem um trato digestivo bastante rudimentar, não possuindo capacidade de digestão enzimática, sendo dependentes das enzimas exógenas (contidas nos alimentos vivos) para a sua digestão.

No caso específico da tilápia, a forma de alimentação na fase larval é bastante importante, pois é durante este período que se faz a reversão sexual, geralmente pela adição de um hormônio masculinizante (17- $\alpha$-metil-testosterona) à ração, a qual é fornecida para os animais durante o primeiro mês de vida (Santiago et al., 1987; Phelps et al., 1995, Carrasco et al., 1999).

Um fator bastante questionado atualmente na piscicultura é o processamento da ração, onde se tem dado bastante atenção às rações extrusadas para juvenis e adultos (Carneiro et al., 1995; Furuya et al., 1997, Kubitza, 1997; Booth et al., 2000), porém de acordo com Lovshin (1997) evidências sugerem que as tilápias utilizam rações fareladas tão eficientemente quanto as peletizadas, em tanques quando estocadas de 1 a 2 indivíduos por $\mathrm{m}^{2}$.

No entanto, para larvas, o problema aumenta, tendo em vista que nesta fase estes indivíduos têm o tamanho bastante reduzido, necessitando de uma ração com tamanho de partícula adequado ao da sua boca (Kubitza, 1997) e a obtenção de extruders de tamanhos adequados a larvas é difícil, além do que o benefício advindo da gelatinização do amido ser de pequena importância visto a pequena quantidade deste nutriente neste tipo de ração.

Portanto, durante a larvicultura da tilápia do Nilo, utiliza-se principalmente a ração farelada, podendo também utilizar-se rações pastosas (Ensminger \& Olentine, 1980) ou micropeletizadas (Santiago et al., 1987). Vale ressaltar que apenas um trabalho foi encontrado na literatura sobre comparação do processamento de rações para larvas de tilápia do Nilo feito por Santiago et al. (1987).

O objetivo do presente trabalho foi o de comparar o efeito de uma ração de mesma composição bromatológica, porém processada de três modos diferentes, sendo uma farelada, uma pastosa e outra micropeletizada, sobre itens de desempenho produtivo como o peso final médio, comprimento final médio, biomassa total final, sobrevivência e condição corporal de larvas de tilápia do Nilo, durante a fase de reversão sexual.

\section{Materiais e Métodos}

O presente experimento foi realizado no Laboratório de Aqüicultura, do Departamento de Biologia na Universidade Estadual de Maringá, durante o período de 23 de outubro a 19 de novembro de 2000.

Foram utilizadas 540 larvas de tilápia do Nilo (Oreochromis niloticus), com dois dias de idade, distribuídas num delineamento completamente casualizado, com três tratamentos e seis repetições, em 18 aquários, onde foi considerado, como unidade experimental, um aquário com 30 larvas.

Os aquários de vidro, apresentavam capacidade total de 57,6 L, entretanto o volume de água utilizado neste experimento foi de $54 \mathrm{~L}$. Possuíam aeração constante por pedra microporosa ligadas por meio de uma tubulação de PVC, a um soprador elétrico monofásico com potência de $1 / 4 \mathrm{cv}$.

A ração experimental (Tabela 1) foi formulada de acordo com exigências propostas por Hayashi et al. (2002) para a tilápia do Nilo durante a fase de reversão sexual, sendo de $38,6 \%$ de proteína digestível e $3800 \mathrm{kcal} / \mathrm{kg}$ de energia digestível. Foi feita a inclusão de hormônio masculinizante (17- $\alpha$-metiltestosterona) na quantidade de $60 \mathrm{mg} / \mathrm{kg}$ de ração (Hayashi, 1995).

Para a elaboração das rações, os ingredientes foram triturados, utilizando-se peneira de $0,5 \mathrm{~mm}$ segundo Hayashi et al. (1999). Devido à alta concentração de gordura na farinha de vísceras e de peixe, antes da moagem, os alimentos foram peneirados manualmente, em malha de $0,5 \mathrm{~mm}$ e em seguida a fração retida foi moída e posteriormente misturado as duas frações. No momento da elaboração das rações foi feita a adição do hormônio masculinizante, de 
acordo com Hayashi (1995).

Posteriormente, o total de ração foi dividida em três partes. A ração farelada foi considerada como a ração obtida depois dos processos anteriormente descritos. A ração pastosa foi considerada como sendo a ração idêntica à farelada, porém no momento do arraçoamento esta era umedecida, misturando-se de 1,3 a 1,5 partes de água para uma parte de ração seca (Ensminger \& Olentine, 1980) e fornecida na forma de uma "bolinha" de cerca de $0,5 \mathrm{~cm}$ de diâmetro. A ração micropeletizada foi obtida com o umedecimento da ração farelada com água a $50^{\circ} \mathrm{C}$ e peletizada manualmente, os peletes então foram moídos e separados do pó e de peletes maiores por passagens em peneiras de diversas malhas (Lovell, 1988), sendo utilizado para as larvas os peletes que passavam na peneira com $1 \mathrm{~mm}$ de abertura e foi considerado pó a fração que passou pela peneira de $0,5 \mathrm{~mm}$.

Os tratamentos constituíram-se do fornecimento, à vontade, de ração na forma farelada, pastosa e micropeletizada, cinco vezes ao dia, às $8 \mathrm{~h}, 10 \mathrm{~h} 30$, 13h30, 15 h30 e $17 \mathrm{~h} 30$.

Os aquários foram sifonados, para a retirada das fezes e restos de ração, duas vezes ao dia, uma durante a manhã (7h00) e outra à tarde (14h30) com a remoção de cerca de $10 \%$ da água nos primeiros dez dias, $20 \%$ até o vigésimo dia e $30 \%$ até final do período experimental.

A temperatura da água foi aferida diariamente pela manhã e à tarde; outros parâmetros como o pH, oxigênio dissolvido e condutividade elétrica da água foram quantificados semanalmente pela manhã sempre antes da sifonagem.

Após o término do período experimental os alevinos foram abatidos por imersão em água gelada (cerca de $2^{\circ} \mathrm{C}$ ), pesados e medidos individualmente para avaliação do peso final médio, comprimento final médio, biomassa final total e fator de condição (obtido através da expressão $\mathrm{wt} / \mathrm{lt}^{3} \mathrm{x} 100$, sendo $\mathrm{wt}=$ peso total $\mathrm{e}$ lt = comprimento total).

Tabela 1 - Fórmula e composição química da ração básica utilizada nos diferentes processamentos Table 1 - Formula and chemical composition of diets used for different processing

\begin{tabular}{|c|c|c|c|}
\hline $\begin{array}{l}\text { Alimento } \\
\text { Food }^{1}\end{array}$ & $\begin{array}{c}\text { Quantidade }(\%) \\
\text { Amount }(\%)\end{array}$ & $\begin{array}{l}\text { Componente } \\
\text { Compound }\end{array}$ & $\begin{array}{c}\text { Quantidade }(\%) \\
\text { Ammount }(\%)\end{array}$ \\
\hline Farinha de vísceras & 29,58 & Proteína digestível & 38,60 \\
\hline Poultry by-products & & Digestible protein & \\
\hline Farelo de soja & 30,00 & Energia digestível ${ }^{3}$ & 3800 \\
\hline Soybean meal & & Digestible energy & \\
\hline Milho & 5,69 & Gordura total & 19,08 \\
\hline Maize & & Total fat & \\
\hline Farinha de peixe & 18,22 & Cálcio & 2,00 \\
\hline Fish meal & & Calcium & \\
\hline Óleo de soja & 9,01 & Fósforo & 1,20 \\
\hline Soybean oil & & Phosphorus & \\
\hline Levedura spray-dried & 6,00 & Fibra bruta & 2,26 \\
\hline Spray-dried yeast & & Crude fiber & \\
\hline Suplemento vit. $\min .^{2}$ & 1,00 & Lisina & 2,77 \\
\hline Min. vit. supplement ${ }^{2}$ & & Lysine & \\
\hline Sal & 0,50 & Metionina + Cistina & 1,81 \\
\hline Salt & & Methionine + Cystine & \\
\hline Antioxidante (BHT) & 0,01 & Ácido linoléico & 6,21 \\
\hline Antioxidant (BHT) & & Linoleic acid & \\
\hline Total & 100,0 & & \\
\hline
\end{tabular}

${ }^{1}$ De acordo com os dados de digestibilidade apresentados por Boscolo et al. (2002) para farelo de soja, milho e óleo de soja; e Meurer et al. (2000) para farinha de vísceras, farinha de peixe e levedura seca por spray dry.

${ }_{1}^{1}$ According with digestible data present from Boscolo et al. (2001) for soybean meal, maize, and soybean oil; and Meurer et al. (2000) for poultry by-products meal, fish meal, and spay-dried yeast.

2 Níveis de garantia por quilograma do produto: Vit. A,1.200.000 UI; Vit. D3, 200.000 UI; Vit. E, 12.000 mg; Vit. K3, 2.400 mg; Vit. B1, 4.800 mg; Vit. B2, 4.800 mg; Vit. B6, 4.000 mg; Vit. B12, 4.800 mg; Ác. fólico, 1.200 mg; Pantotenato Ca, 12.000 mg; Vit. C, 48.000 mg; Biotina, 48 mg; Colina, 65.000 mg; Niacina, 24.000 mg; Ferro, 10.000 mg; Cobre, 6.000 mg; Manganês, 4.000 mg; Zinco, 6.000 mg; lodo, 20 mg; Cobalto, $2 \mathrm{mg}$; Selênio, $20 \mathrm{mg}$.

2 Levels by kilogram of product: Vit. A, 1,200,000 UI; Vit. D, 200,000 UI; Vit. E, 12,000 mg; Vit. K3, 2,400 mg; Vit. B1, 4,800 mg; Vit. B2, 4,800mg; Vit. B6, 4,000 mg; Vit. B12, 4,800 mg; Folic acid, 1,200 mg; Pantotenato Ca, 12,000 mg; Vit. C, 48,000 mg; Biotin, 48 mg; Colin, 65,000 mg; Niacin, 24,000 mg; Fe, $10,000 \mathrm{mg} ; \mathrm{Cu}, 6,000 \mathrm{mg} ; \mathrm{Mn}, 4,000 \mathrm{mg} ; \mathrm{Zn}, 6,000 \mathrm{mg} ; \mathrm{I}, 20 \mathrm{mg}$; Co, $2 \mathrm{mg} ; \mathrm{Se}, 20 \mathrm{mg}$.

$3 \mathrm{kcal} / \mathrm{kg}$. 
O modelo estatístico utilizado foi:

$$
Y_{i j}=\mu+T_{i}+e_{i j}
$$

em que $Y_{\mathrm{ij}}$ é observação do grupo de larvas j submetidos à ração com processamento $\mathrm{i} ; \mu$, constante inerente às observações; $T_{i}$, efeito da ração com processamento $\mathrm{i}$; $\mathrm{e}_{\mathrm{ij}}$, erro aleatório associado a cada observação.

De posse dos dados de desempenho, os mesmos foram submetidos à análise de variância e os contrastes entre médias comparados pelo teste de NewmanKeuls a 5\% de probabilidade, utilizando-se o programa computacional SAEG - Sistema de Análises Estatísticas e Genéticas (UFV, 1997).

\section{Resultados e Discussão}

Os parâmetros físico-químicos da água $\mathrm{pH}$, condutividade $(\mu \mathrm{S} / \mathrm{cm})$ e oxigênio dissolvido $(\mathrm{mg} / \mathrm{L})$, foram de, respectivamente, $6,9 \pm 0,2 ; 161,2 \pm 15$ e 4,6 $\pm 0,5$, mantiveram-se dentro dos padrões recomendados para a aquicultura (Boyd, 1990; Popma \& Phelps, 1998). A temperatura da água foi de $21,9 \pm 0,1^{\circ} \mathrm{C}$ de manhã e $22,7 \pm 0,3^{\circ} \mathrm{C}$ à tarde, abaixo do recomendado por Popma \& Phelps (1998) para o bom desempenho da espécie, entretanto, mesmo com a baixa temperatura da água, o desempenho apresentado pode ser considerado bom.

Os resultados finais médios de peso, comprimento, condição corporal, sobrevivência e biomassa, das larvas de tilápia do Nilo submetidas às rações com diferentes processamentos estão apresentados na Tabela 2.

$\mathrm{O}$ peso final e a condição corporal médias das larvas de tilápia do Nilo não foram influenciados pelo processamento da ração ( $\mathrm{P}>0,05)$, estando os dados de peso final médio de acordo com os resultados apresentados por Santiago et al. (1987), que trabalharam com a comparação de dietas fareladas e micropeletizadas para larvas de tilápia do Nilo e com Hayashi et al. (2001) comparando a influência do processamento da ração no desempenho de larvas de carpa cabeça grande (Aristichthys nobilis).

As larvas submetidas ao tratamento com ração farelada apresentaram o comprimento final médio superior $(\mathrm{P}<0,05)$ aos das larvas alimentadas com a ração micropeletizada, entretanto os resultados do tratamento com ração pastosa foram semelhantes aos demais tratamentos. Resultado que descorda dos apresentados por Santiago et al. (1987) e Hayashi et al. (2001), onde o processamento da ração não influenciou este parâmetro.

A sobrevivência das larvas alimentadas com as rações farelada e pastosa apresentaram uma sobrevivência semelhante, porém superior $(\mathrm{P}<0,05)$ em relação às larvas submetidas a ração micropeletizada, o que descorda de Santiago et al. (1987), que apresentaram uma situação inversa, onde a sobrevivência das larvas submetidas a ração micropeletizada foi superior ao da farelada. Tal resultado também não está de acordo com os resultados apresentados Hayashi et al. (2001), onde a ração pastosa levou a uma sobrevivência superior à da ração micropeletizada, entretanto a sobrevivência das larvas submetidas à ração farelada não diferiu das demais.

A biomassa total produzida foi superior $(\mathrm{P}<0,05)$ para as larvas alimentadas com as dietas fareladas em relação aos tratamentos com ração pastosa e

Tabela 2 - Valores de desempenho e sobrevivência das larvas de tilápia do Nilo submetidas à rações com diferentes processamentos

Table 2 - Performance and survival values of Nile tilapia fry submitted to different processing diets

\begin{tabular}{|c|c|c|c|c|}
\hline $\begin{array}{l}\text { Resultados } \\
\text { Results }\end{array}$ & $\begin{array}{c}\text { Farelada } \\
\text { Meal }\end{array}$ & $\begin{array}{c}\text { Pastosa } \\
\text { Pasty }\end{array}$ & $\begin{array}{c}\text { Micropeletizada } \\
\text { Crumble }\end{array}$ & $\mathrm{CV}(\%)$ \\
\hline $\begin{array}{l}\text { Peso final médio(g) } \\
\text { Final weight }(g)\end{array}$ & 0,51 & 0,43 & 0,41 & 19,74 \\
\hline $\begin{array}{l}\text { Comp. final médio }(\mathrm{cm}) \\
\text { Final length }(\mathrm{cm})\end{array}$ & $2,92 \mathrm{a}$ & $2,80 \mathrm{ab}$ & $2,68 b$ & 5,52 \\
\hline Condição corporal & 2,04 & 1,97 & 2,08 & 6,10 \\
\hline $\begin{array}{l}\text { Corporal condition } \\
\text { Sobrevivência }(\%) \\
\text { Survival rate }(\%)\end{array}$ & $97,77 \mathrm{a}$ & $96,86 a$ & $86,66 b$ & 7,02 \\
\hline $\begin{array}{l}\text { Biomassa final }(\mathrm{g}) \\
\text { Final biomass }(\mathrm{g})\end{array}$ & $15,09 \mathrm{a}$ & $12,05 b$ & $10,48 b$ & 17,55 \\
\hline
\end{tabular}

Número seguido de letra na mesma linha demonstra diferença $(p>0,05)$ pelo teste Newman-Keuls.

Number following of a letter at same line show difference $(p>.05)$ by Newman-Keuls test.

R. Bras. Zootec., v.32, n.2, p.262-267, 2003 
micropeletizada, que foram semelhantes entre si. Resultados que não concordam com os apresentados por Hayashi et al. (2001), para a carpa cabeça grande, onde o melhor resultado de biomassa final foi alcançado no tratamento com ração pastosa e o pior com a ração farelada, sendo que a ração micropeletizada não diferiu destes dois tratamentos.

Ao relacionar os dados obtidos neste experimento pode ser notado o melhor desempenho geral das larvas obtidas com a dieta farelada em relação aos demais tratamentos, demonstrado principalmente pela maior biomassa final, parâmetro este que relaciona o peso final médio com a sobrevivência final, sendo de grande importância prática pois é o resultado final esperado em uma criação comercial.

Pezzato (1999) cita que um dos problemas da ração farelada é a separação dos seus ingredientes quando fornecida aos animais, podendo possibilitar a seletividade por parte das larvas, entretanto parece haver uma baixa capacidade de seletividade desta espécie nesta fase.

Já Lovell (1988) cita que as dietas fareladas permanecem por mais tempo na superfície da água diminuindo a lixiviação dos seus nutrientes quando comparada a rações com partículas que afundam quando em contato com a água; este fato pode ter sido importante nos resultados obtidos neste experimento pois a ração farelada realmente ficava na superfície da água, enquanto as rações micropeletizadas e pastosa afundavam rapidamente. Contrapondo-se às citações de Kubitza (1997) que uma das vantagens das rações peletizadas é a menor perda de nutrientes solúveis (como vitaminas e minerais), e Dupree (1984) citando que a lixiviação dos nutrientes é muito rápida e intensa em rações fareladas, devido à sua alta relação entre a área superficial e o volume, citações estas que, com certeza, aplicam-se melhor a animais adultos que a larvas.

A ração farelada é a de processamento mais simples e barato, dentre os testados, pois envolve apenas a moagem e a mistura dos alimentos, sendo necessário apenas um aparelho de moagem e um misturador. A ração pastosa é um processamento quase tão simples quanto o anterior; utiliza a mesma aparelhagem, porém envolve um pequeno aumento de mão de obra para o umedecimento da mesma. Já a micropeletização é um processamento mais complicado e caro que os anteriores, pois exige uma peletizadora, além dos demais equipamentos de moagem e mistura. Outro fator que onera o processo é a necessidade da diminuição do tamanho dos peletes, para que estes se adeqüem ao tamanho da boca das larvas, que é feito pela quebra dos peletes e a passagem deste material através de peneiras com malhas de diversos tamanhos.

Um fator importante na formulação das rações artificiais para larvas é o grau de moagem do alimento e também do grânulo do micropelete, onde deve ser dada preferência para tamanhos menores que $0,5 \mathrm{~mm}$ (Lovell, 1988; Kubitza, 1997). Porém, quanto mais fina a moagem, mais caro fica o processo, pois aumenta-se o tempo gasto, consequentemente o gasto com mão-de-obra e energia.

Considerando os resultados apresentados por Santiago et al. (1987) em relação aos do presente experimento, notam-se resultados contraditórios, que podem ser explicados pela diferença no tamanho da partícula do alimento e do micropelete utilizados pelos autores anteriormente citados $(0,25 \mathrm{~mm}$ para a ração farelada e a micropeletizada entre 0,25 a $0,35 \mathrm{~mm}$ ) e os do presente experimento. Isto nos leva a pressupor que obtêm-se melhores resultados com rações micropeletizadas em comparação à farelada quando se utiliza uma moagem mais fina $(0,25 \mathrm{~mm})$ e quando se faz uso de uma moagem mais grosseira $(0,5 \mathrm{~mm})$ a ração farelada apresenta melhores resultados.

\section{Conclusões}

De acordo com os resultados apresentados neste experimento, utilizando-se a moagem dos ingredientes da ração em peneira de $0,5 \mathrm{~mm}$, para larvas de tilápia do Nilo durante a reversão sexual, recomendase a utilização de ração na forma farelada, pois esta promove melhor sobrevivência e biomassa final.

\section{Literatura Citada}

AJAH, P.O. Effects of live foods, artificial feed and their combination on growth and survival of African Clariid Catfish (Heterobranchus longiifilis Valenciennes, 1840) larvae. Bamidgeh, v.40, n.4, p.205-213, 1997.

BOOTH, M.A.; ALLAN, G.L.; WARNER-SMITH, R. Effects of grinding, steam conditioning and extrusion of a practical diet on digestibility and weight gain of silver perch,Bidyanus bidyanus. Aquaculture, n.182, p.287-299, 2000.

BOSCOLO, W. R.; HAYASHI, C.; MEURER, F. Digestibilidade aparente da energia e proteína bruta de alguns alimentos pela tilápia do Nilo (Oreochromis niloticus). Revista Brasileira de Zootecnia, v.31, n.2, p.539-545, 2002.

BOYD, C. Water quality in ponds for aquaculture.London: Birmingham Publishing Co, 1990. 482p.

CARNEIRO, D.J.; CHAIM, S.H.S.; DIAS, T.C.R. Efeito do 
processamento das dietas comerciais sobre o desenvolvimento produtivo do pacú, Piaractus mesopotamicus(Holmberg, 1887). In: SIMPÓSIO BRASILEIRO DE AQÜICULTURA, 7., 1995, Peruíbe. Anais...Peruíbe: SIMBRAq, 1995. p.44. CARRASCO, L.A.P.; PENMAN, D.J.; VILLALOBOS, S.A. et al. The effects of oral administration with $17 \mathrm{a}-$ methyltestosterone on chromosomal synapses in Oreochromis niloticus (Pisces, Cichlidae). Mutation Research, v.430, p.87-98, 1999.

CESTAROLli, M.A.; PORTELLA, M.C.; ROJAS, N.E.R. Efeito do nível de alimentação e do tipo de alimento na sobrevivência e no desempenho inicial de larvas de curimbatá Prochilodus scrofa (Steindachner, 1881). Boletim do Instituto de Pesca, v.24, p.119-129, 1997.

DILAURO, M.N.; KRISE, W.F. Growth and survival of Lake Sturgeon larvae fed formulated diets. The Progressive FishCulturist, v.60, p.293-296, 1998.

DUPREE, H.K. Feeding practices. In: ROBINSON, E. N. (Ed.) Nutrition and feeding of channel catfish. Auburn: Southern Cooperative, 1984, p.51-54.

ENSMINGER, M.E.; OLENTINE, C.G. Feeds \& nutrition. California:Ensminger Publishing Company, 1980. 1417p.

FERMIN, A.C.; RECOMENTA, R.D. Larval rearing of bighead carp, Aristichthys nobilis Richardson, using different types of feed and their combinations.Aquaculture and Fisheries Management, v.19, n.3, p.283-290, 1988.

FURUYA, W.M.; FURUYA, V.B.; SOUZA, S.R. Desempenho de tilápias do Nilo (Oreochromis niloticus L.), submetidas a dietas farelada, peletizada e extrusada, na terminação. In: REUNIÃO ANUAL DA SOCIEDADE BRASILEIRA DE ZOOTECNIA, 34., 1997, Juiz de Fora.Anais...Juiz de Fora: Sociedade Brasileira de Zootecnia, 1997. p.230-231.

GALVÃO, M.S.N.; FENERICH-VERANI, N.; YAMANAKA, N. et al. Histologia do sistema digestivo da tainha Mugil platanus Günther, 1880 (Osteichthyes, Mugilidae) durante as fases larval e juvenil.Boletim do Instituto de Pesca, v.24, p.91-100, 1997.

HAYASHI, C. Breves considerações sobre as tilápias. In: RIBEIRO, R.P.; HAYASHI, C.; FURUYA, W.M. (Eds.).Cursode piscicultura - criação racional de tilápias. 1.ed. Maringá: Eduem, 1995. p.4.

HAYASHI, C.; BOSCOLO, W.R.; SOARES, C.M. et al. Uso de diferentes graus de moagem dos ingredientes em dietas para a tilápia do Nilo Oreochromis niloticus L.) na fase de crescimento. Acta Scientiarum, v.21, n.3, p.733-737, 1999.

HAYASHI, C.; BOSCOLO, W.R; MEURER, F. et al. Desempenho de larvas de carpa cabeça grande (Aristichthys nobilis), alimentadas com plâncton, ração micropeletizada, farelada e pastosa. In: REUNIÃO ANUAL DA SOCIEDADE BRASILEIRA DE ZOOTECNIA, 38., 2001, Piracicaba. Anais... Piracicaba: Sociedade Brasileira de Zootecnia, 2001. p.1419.

HAYASHI, C.; BOSCOLO, W.R.; SOARES, C.M. et al. Exigência de proteína digestível para larvas de tilápia do Nilo no período de reversão sexual. Revista Brasileira de Zootecnia, no prelo. 2002.

KUBITZA, F. Nutrição e alimentação dos peixes.Piracicaba: Escola Superior de Agricultura Luiz de Queiroz, 1997. 74p.

LAHAV, E.; RA'NAN, Z. Salinity tolerance of genetically produced tilapia (Oreochromis) hybrids. Bamidgeh, v.49, n.3, p.160-165, 1997.

LOVELL, T. Nutrition and feeding of fish. New York:Van Nostrand and Reinhold, 1988. 260p.
LOVSHIN, L.L. Tilápia farming: a growing worldwild aquaculture industry. In: SIMPÓSIO SOBRE MANAJO E NUTRIÇÃO E PEIXES, 1., 1997, Piracicaba.Anais... Piracicaba: Colégio Brasileiro de Nutrição Animal, 1997. p.137.

MEURER, F.; HAYASHI, C.; BOSCOLO, W.R. Digestibilidade aparente da proteína bruta, matéria seca e energia bruta de alguns alimentos protéicos para tilápia do Nilo (Oreochromis niloticus, L). In: SIMPÓSIO BRASILEIRO DE AQÜICUlTURA, 11., 2000, Florianópolis. Anais... Florianópolis: SIMBRAq, 2000.

MEURER, F.; HAYASHI, C.; BOSCOLO, W.R. et al. Lipídeos na alimentação de alevinos revertidos de tilápia do Nilo (Oreochromis niloticus L.). Revista Brasileira de Zootecnia, v.31, n.2, p.566-573, 2002

PEZZATO, L.E. Alimentação de peixes - Relação custo benefício. In: REUNIÃO ANUAL DA SOCIEDADE BRASILEIRA DE ZOOTECNIA, 36, 1999, Porto Alegre. Anais... Porto Alegre:SBZ, 1999. p.109.

PHELPS, R.P.; SALAZAR, G.C.; ABE, V.; et al. Sex reversal and nursery growth of Nile tilapia, (Oreochromis niloticus, L.), free-swimming in earthen ponds. Aquaculture Research, n.26, p.293-295, 1995.

POPMA, T.J.; PHELPS, R.P. Status report to commercial tilápia producers on monosex fingerling productions techniques. In: SIMPÓSIO SUL AMERICANO DE AQUICULTURA, 1., 1998, Recife.Anais... Florianópolis: SIMBRAQ, 1998. p.127.

QUIN, J.; FAST, A.W.; DEANDA, D. et al. Growth and survival of larval snakehead (Channa striatus) fed different diets. Aquaculture, v.148, n.2/3, p.105-113, 1997.

RADÜNZ-NETO, J. Alimentação natural X ração balanceada na larvicultura de peixes. In: REUNIÃO ANUAL DA SOCIEDADE BRASILEIRA DE ZOOTECNIA, 36., 1999, Porto Alegre. Anais... Porto Alegre: Sociedade Brasileira de Zootecnia, 1999. p.119.

SANTIAGO, C.B.; ALDABA, M.B.; REYES, O.S. Influence of feeding rate and diet from on growth and survival of Nile tilapia (Oreochromis niloticus) fry. Aquaculture, v.64, p.277-282, 1987.

SOARES, C.M.; HAYASHI, C.; FURUYA, W.M. et al. Alimentação do natural do cascudo pretoRhinelepis asperaAgassiz, 1829 (Osteichthyes, Loricariidae) em tanques de cultivo. Boletim do Instituto de Pesca, n.24, p.109-117, 1997.

SOARES, C.M.; HAYASHI, C.; GONÇALVES, G.S. Plâncton, Artemia sp, dieta artificial e suas combinações no desenvolvimento e sobrevivência do quinguio (Carassius auratus) durante a larvicultura. Acta Scientiarum, v.22, n.2, p.383$388,2000$.

SOUZA, S.R.; HAYASHI, C.; GALDIOLI, E.M. et al. Diferentes fontes de protéicas de origem vegetal para a tilápia do Nilo, durante a reversão sexual. In: REUNIÃO ANUAL DA SOCIEDADE BRASILEIRA DE ZOOTECNIA, 37., 2000, Viçosa, MG. Anais... Viçosa, MG: Sociedade Brasileira de Zootecnia, [2000]. CD-ROM.

UNIVERSIDADE FEDERAL DE VIÇOSA - UFV.SAEG Sistema para análises estatísticas e genéticas. Versão 7.1. Viçosa, MG. 150p. (Manual do usuário).

Recebido em: 16/04/02 Aceito em: 16/09/02 